\title{
Dimensions Of Competitive Priorities: Are They Clear, Communicated, And Consistent?
}

Sohel Ahmad, (Email: ahmad@stcloudstate.edu), St. Cloud State University Roger G. Schroeder, (Email: rschroeder@csom.umn.edu), University of Minnesota

\begin{abstract}
In spite of convincing theoretical arguments in the literature, very little attention is paid to empirically identifying the dimensions of competitive priorities. The present study identifies these dimensions and relates them to Porter's cost-differentiation strategy framework. Although the majority of the manufacturing plants ranked quality as the most important competitive priority, it could not foster differentiation by itself. Subsequent analyses show that while plants pursuing differentiation strategy were proactive in two administrative activities (communication of manufacturing strategy and establishment of formal strategic planning), plants pursuing low-cost strategy were not, suggesting that the managers of these plants pay close attention to these administrative activities.
\end{abstract}

\section{Introduction}

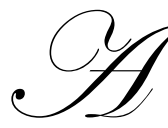

ny organization that wants to successfully compete in the marketplace must focus on customer requirements. These requirements can be numerous even for a narrow customer segment. An organization must translate customer requirements into objectives for operations known as competitive priorities. Examples of competitive priorities include low cost, consistent quality, and on-time delivery.

Operations (manufacturing) is one of the primary activities of the value chain (Porter, 1990). Therefore, identifying appropriate objectives and attaching requisite importance to these objectives at the operations level cannot be overemphasized. Competitive priorities play an important role in technology adoption, process choice, capacity management, manufacturing planning and control systems, employee skill development and quality assurance (Hayes and Wheelwright, 1984). Once identified, competitive priorities can guide pertinent resource allocation to meet operations' objectives.

From a theoretical standpoint, researchers have acknowledged low cost, quality, delivery, and flexibility as the four dimensions of competitive priorities. However, so far the literature pays very little attention to empirically validating these dimensions. The goal of this study is to empirically identify and validate the dimensions of competitive priorities.

\section{Literature Review and Research Questions}

\section{Competitive Priorities}

Hayes and Wheelwright (1984) define competitive priorities as strategic preferences or the ways in which an organization chooses to compete in the marketplace. Leong, Snyder, and Ward (1990), focusing on operations,

Readers with comments or questions are encouraged to contact the authors via email.

identify competitive priorities as a consistent set of goals for manufacturing to gain competitive advantage. Several other terms are also used in the literature to refer to competitive priorities such as organizational priorities, content variables, dimensions of competition, core content, manufacturing tasks, order winners and qualifiers etc. (Skinner, 
1969; Adam \& Swamidass, 1989; Ferdows \& De Meyer, 1990; Fitzsimmons, Kouvelis, \& Mallick, 1991; Berry, Bozarth, Hill, \& Klompmaker, 1991; Vickery, Droge, \& Markland, 1993; Krajewski \& Ritzman, 1996). Despite semantic differences, broad agreement exists in the literature to theoretically classify competitive priorities into the following four basic components: low cost, quality, delivery performance, and flexibility (Hayes \& Wheelwright, 1984; Ward, Duray, Leong, \& Sum, 1995). A fifth competitive priority - innovativeness - has been suggested (Leong, Snyder, and Ward, 1990) and is gradually gaining recognition.

The importance of identifying and pursuing appropriate competitive priorities at the operations level was emphasized a long time ago (Skinner, 1966, 1969). Over the years, several authors (Wheelwright, 1978; Schmenner, 1981; Hayes \& Wheelwright, 1984) have theoretically argued for a wide variety of competitive priorities and proposed a number of criteria for evaluating manufacturing performance. Later, empirical studies on this topic investigated the relationship between production competence and business success (Cleveland, Schroeder and Anderson, 1989), the impact of intended and achieved competitive priorities on a firm's financial performance (Wood, Ritzman and Sharma, 1990), the influence of competitive priorities on lasting improvements in manufacturing performance (Ferdows and Meyer, 1990) and so on. Despite many years of strong theoretical arguments for four/five dimensions of competitive priorities at the operations level, no attempts were made to empirically validate these dimensions until recently.

Vickery, Droge, and Markland (1997) identified four dimensions (factors) of manufacturing strength by factor analyzing performance ratings on ten manufacturing competitive priorities in the furniture industry. These factors, therefore, represent the dimensions of performance achieved on competitive priorities rather than dimensions of competitive priorities themselves. While competitive priorities are an organization's set of goals or strategic preferences chosen to compete in the marketplace, performance ratings represent achievement along those goals. Two organizations may choose to pursue the same competitive priority yet their performance on that competitive priority may vary widely. For example, an organization may choose on-time delivery as its competitive priority; however, whether it achieves superior on-time delivery performance or not depends on several factors including allocation of pertinent resources, implementation of appropriate management practices (e.g., Just-In-Time), the relationship with the suppliers and so on. Hence, an organization's performance may not reflect its strategic preferences or goals. We, therefore, believe that identification of dimensions of competitive priorities themselves is as important, if not more important, than identification of the dimensions of performance to understand organizations' strategic preferences. Accordingly, we attempt to identify the dimensions of competitive priorities in the present study.

Question 1 - What are the dimensions of competitive priorities in manufacturing organizations?

\section{Administrative Activities}

Identification of appropriate competitive priorities is an essential part of developing a manufacturing strategy. Decisions regarding manufacturing strategy are typically made at higher levels of management in organizations. Academics and practitioners have long asserted that these decisions and their context specific implications should be clearly communicated throughout the organization (Skinner, 1969; Porth, Kathuria \& Joshi, 1998). Moreover, the need for instituting formal strategic planning process which results in a written mission, goals, and plans for achieving such goals has also been strongly emphasized in the literature (Garvin, 1993). Therefore, in order to make a manufacturing strategy effective, attention should be paid to the following administrative activities: (1) communicating manufacturing strategy to employees at all levels of the organization (COMM); and (2) establishing a formal strategic planning process (FORMAL). These administrative activities are important for the following reasons. First, COMM --communication of manufacturing strategy and long-term goals to all employees -- fosters consistent tactical decision making since the employees become aware of how the organization is attempting to be competitive. Often organizations discover that activities carried out by various functional units are not coordinated due to lack of communication (Garvin, 1993). Secondly, FORMAL -- establishment of a formal strategic planning process -- emphasizes that the mission, long-range goals and strategies be institutionalized through active involvement of representatives from all functional units including employees from operations. Such institutionalization of the strategic planning process makes knowledge and learning organization-owned rather than individual-owned (Glynn, 1996). Therefore, an organization is less susceptible to failure to achieve its goals just because one or two key employees 
leave the organization. Furthermore, formalization of the strategic planning process enables an organization to document changes in its strategic plan due to changes in the competitive environment. These documents can help reassess an organization's past strategic actions and their outcomes and can provide valuable input to the development of future strategic plans, thus facilitating strategic renewal (Floyd \& Lane, 2000).

These two administrative activities help employees make informed, coordinated and consistent decisions at different levels to achieve business success. As such, these activities are important regardless of which competitive priority is pursued. In the present exploratory study, we investigate the validity of this assertion.

Question 2 - Are the extent of efforts put into administrative activities independent of the competitive priority pursued by an organization?

\section{Data Collection}

Data were collected from manufacturing plants under the World Class Manufacturing (WCM) project. This is an on going research project intended to investigate management practices in different industries and countries. Stratified random sample design was used where each industry and country combination constituted a stratum. Plants were randomly selected within each stratum and the managers of these plants were asked for their voluntary participation in this project. A plant research coordinator, appointed by the plant manager, maintained close contact with the research team. Typically, these plant research coordinators were managers who had knowledge about the major responsibilities of the employees. The research team consulted with the coordinators to identify respondents capable of providing accurate and unbiased data. Per our instructions, the plant research coordinators collected the questionnaires in sealed envelops to maintain anonymity of responses.

The data collection instrument was pilot tested at several plants to obtain feedback from managers, superintendents, engineers, and workers. The feedback helped clarify the language of some questions (items) used in scales. The questionnaires were first translated into the respective languages and then translated back into English and compared with the original English version. Inconsistencies were resolved before administering the questionnaires in Germany, Italy and Japan. Overall, sixty-six percent of the plants contacted returned the questionnaires.

We use a subset of the data collected in the WCM project for the present study. This includes 103 plants, after eliminating observations with missing data, from the automobile, electronics and machinery industries in four countries: Germany, Italy, Japan, and the U.S.A. These plants on average employ 997 employees, including both salaried and hourly workers. The average age of these plants is about 35 years, and average facility size is 127,467 square feet. These plants manufacture 32 product lines on average capturing about 34 percent of their main products' market share.

\section{Measurement, Analysis and Results}

\section{The Dimensions of Competitive Priorities}

Consistent with the literature, we measure competitive priorities as the "degree of emphasis" an organization places on its objectives to secure and sustain its competitive advantage (Ward, Duray, Leong, \& Sum, 1995). Eight competitive priorities (objectives) were identified based on the operations management literature discussed earlier. Plant research coordinators were asked to rank these objectives. See Appendix A for details. A company may place high emphasis on more than one objective (Corbett \& Wassenhove, 1993; Ferdows \& De Meyer, 1990). In order to reflect this possibility in the responses, we allowed the respondents to rank several objectives the same if they were considered to be of equal importance. These ratings were then used as input for a principal components factor analysis with varimax rotation to identify the dimensions of competitive priorities. Four factors (dimensions) were identified for the following reasons (see Table 1). The 'eigen value greater than 1' rule is generally used as a cut-off value. This criterion yielded four factors. The scree plot also pointed to four factors. The variation explained by these four factors accounted for 79.26 percent. Moreover, the loading of each of the competitive priorities on its respective factor was at least 0.60 which is considered substantial (Porth, Kathuria \& Joshi, 1998; Ward, McCreery, Ritzman \& Sharma, 1998). Additionally, these factors did not exhibit cross-loading problems; the difference between the highest and second highest weights (loads) for any given item was less than 0.10 across factors (Dean \& 
Snell, 1996).

Table 1

Factor Analysis of Competitive Priority Measures with Varimax Rotation

\section{Competitive priorities}

Dependable delivery (DEPENDEL)

Fast deliveries (FASTDEL)

Ability to rapidly introduce new products or make design changes (NEWPROD)

High performance products (HIGHPERF)

Low unit cost (COST)

Ability to make rapid volume changes (VOLCHNG)

Low manufacturing cycle time (CYCLETM)

Consistent quality (CONSQUAL)

Eigenvalue

Percent of variance explained

Cumulative percent variance explained

\begin{tabular}{c}
$\begin{array}{c}\text { Delivery im- } \\
\text { portance }\end{array}$ \\
Factor 1 \\
\hline 0.93 \\
0.84 \\
0.09 \\
\\
0.16 \\
-0.07 \\
0.33 \\
0.47 \\
0.15 \\
3.06 \\
38.26 \\
38.26
\end{tabular}

Rotated factor pattern

Innovation Efficiency importance importance Factor 2

0.07

0.25

0.88

$\underline{\text { Factor } 3}$

0.01

0.16

$-0.03$

0.75

$-0.06$

0.39

0.29

0.08

1.18

14.77

53.03
0.19

0.91

0.61

0.60

0.10

1.09

13.63

66.66

\begin{tabular}{c}
$\begin{array}{c}\text { Quality } \\
\text { importance } \\
\text { Factor 4 }\end{array}$ \\
\hline 0.02 \\
0.22 \\
0.04 \\
\\
0.03 \\
0.14 \\
0.07 \\
-0.37 \\
0.95 \\
1.01 \\
12.60 \\
79.26
\end{tabular}

Factor 1 represents delivery importance and encompasses both delivery reliability and delivery speed. Delivery dependability/reliability is critical in organizations where principles of lean production are emphasized. Delivery speed shortens customer response time and helps gain competitive advantage. Factor 2 involves speed of new product introduction and design changes to existing products. This factor also includes a plant's emphasis on developing high performance products. Developing new products quickly and adding extra features to existing products can be a viable way to compete. Efficiency importance is represented by Factor 3. This factor incorporates a plant's emphasis on low unit cost and low manufacturing cycle time while attaining volume flexibility. Competing on the basis of efficiency is suited for a market segment that deals with standardized high volume products where low unit cost is considered more important than extra features of the product. The final dimension, factor 4 , represents a plant's emphasis on consistent quality. In other words, this factor stresses conformance to product specifications (conformance quality) for the products produced by the plants.

Overall, these four factors reflect the competitive priority dimensions argued in the literature namely, low cost, quality, delivery, flexibility, and innovativeness (Hayes \& Wheelwright, 1984; Leong, Snyder, \& Ward, 1990; Ward, Duray, Leong, \& Sum, 1995). In our empirical analysis no factor was labeled "flexibility." However, this dimension was subsumed within Factor 2 and Factor 3. In general, flexibility in production can be broadly classified into two types: scale flexibility (also called volume flexibility) and scope flexibility (product-mix flexibility). The results of our empirical analysis show that the ability to make rapid volume changes (scale flexibility) loaded on to Factor 3. Therefore, Factor 3 does not merely represent efficiency importance but more appropriately represents cost-efficient scale flexibility importance. The scope flexibility (product-mix flexibility), on the other hand, was subsumed in Factor 2.

\section{The Criterion-Related Validity}

Having identified four dimensions (factors) of competitive priorities, we now establish their criterionrelated validity (also termed predictive validity). The criterion-related validity involves determining the extent to which a measure of a construct (here a dimension of the competitive priorities) can predict the measure of a theoretically related construct (Schwab, 1980). Porter's (1985) low-cost and differentiation strategy framework can serve as a theoretically related construct for this purpose. While this framework is conceptualized at the strategic business unit (SBU) level, the dimensions of competitive priorities are conceptualized and measured at the operations level. According to Porter (1985), an SBU can gain a sustainable competitive advantage over other firms in its industry by pursuing a "low-cost strategy" or a "differentiation strategy." In a low-cost strategy, a firm exercises tight operating and overhead cost control to achieve an efficient-scale facility. However, in a differentiation strategy, a firm attempts to be unique in its industry by highlighting one or more attributes perceived important by prospective customers. In light of Porter's (1985) framework, the four dimensions of competitive priorities at the operations level 
can be theoretically categorized into low-cost and differentiation strategy at the strategic business unit level as follows: (1) "Low-cost" corresponds to "efficiency importance" and (2) "Differentiation strategy" corresponds to "Delivery importance," "Innovation importance," or "Quality importance."

Therefore, in order to demonstrate the criterion-related validity of the dimensions of competitive priorities, we need to show that these dimensions predict Porter's low-cost and differentiation strategy framework. Govindarajan (1988) developed an instrument to measure where an organization's strategy falls within the low-cost strategy and differentiation strategy continuum. We use this instrument which consists of six items, in our study (See Appendix A). Plant managers were asked to compare the products produced at their plants to their competition in the following six areas: product selling price, percent of sales spent on $\mathrm{R} \& \mathrm{D}$, percent of sales spent on marketing expenses, product quality, brand image, and product features. A composite variable (COSTDIFF) was formed by adding the scores of the six items. A high value of this variable (COSTDIFF) indicated a strong differentiation strategy and a low value indicated a strong low-cost strategy.

Also, we formed competitive priority dimension variables by taking the average of the respective items that loaded on each factor. This yielded four variables representing competitive priority dimensions as follows:

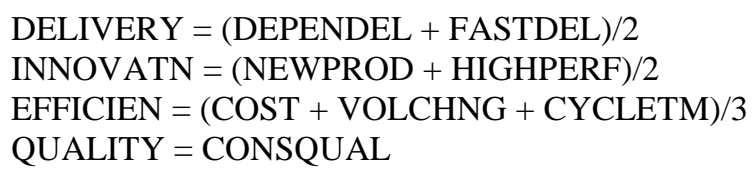

According to the above measurement schemes, we will find support for the criterion-related validity of the competitive priority dimensions if we find the following:

1. COSTDIFF is negatively related to DELIVERY

2. COSTDIFF is negatively related to INNOVATN

3. COSTDIFF is positively related to EFFICIEN

4. COSTDIFF is negatively related to QUALITY

(Note that a lower value of each of the variables DELIVERY, INNOVATN, EFFICIEN, or QUALITY indicates a more important objective. However, a lower value of the variable COSTDIFF indicates a strong low-cost strategy.)

Importantly, Porter's later work emphasizes "focus strategy" as the third generic competitive strategy (Porter, 1990). This strategy differs from the other two (low-cost and differentiation) chiefly because it is directed toward serving the needs of a narrow target (e.g., particular market segment, geographic market, etc.). Once a particular market niche is chosen, an organization can pursue its focus strategy through either a differentiation (focused differentiation) or a low-cost (cost focus) approach. Much research has been conducted in last decade using Porter's later work (Kumar, Subramanian, \& Yauger, 1997; Kotha \& Vadlamani, 1995; Jennings \& Lumpkin, 1992). However, we did not incorporate "focus strategy" in our analysis because we used Govindarajan's (1988) instrument, which was intended to measure an organization's position within the low-cost strategy and differentiation strategy continuum.

The factors that influence an organization's decision about which competitive strategy to pursue are varied. Researchers have argued that environmental concerns such as the industry in which an organization competes can greatly influence this decision (Dess, Ireland, and Hitt, 1990; Ward, Duray, Leong, \& Sum, 1995). For example, an organization producing communication equipment is more likely to compete on the basis of innovation than an organization producing plastic containers for domestic use. Similarly, the notion of competitive advantage of nations by Porter (1990) suggests that the country in which an organization is based can and does influence the choice of competitive priorities and their relative success. Since both of these environmental factors, industry and country, can greatly influence competitive strategy decisions, their effects need to be controlled when we examine the relationship between Porter's low-cost and differentiation strategy and the dimensions of competitive priorities.

In the past, some studies have attempted to control for environmental effects by limiting the study to a single industry and country at the expense of generalizability of the findings (Vickery, Droge, \& Markland, 1997). We 
intended to avoid this shortcoming by using a data set that includes plants from multiple countries and industries. We formed indicator variables representing these countries and industries as follows: GER (Germany compared to USA); ITA (Italy compared to USA); JAP (Japan compared to USA); MAC (Machinery industry compared to Electronics industry); and AUT (Automobile industry compared to Electronics industry). We then controlled for environmental effects by introducing these indicator variables in the following regression equation:

$$
\begin{aligned}
& \text { COSTDIFF }=\beta_{0}+\beta_{1} G E R+\beta_{2} I T A+\beta_{3} J A P+\beta_{4} M A C+\beta_{5} A U T+\beta_{6} D E L I V E R Y+ \\
& \beta_{7} I N N O V A T N+\beta_{8} E F F I C I E N+\beta_{9} \text { QUALITY }[1]
\end{aligned}
$$

The results of this regression analysis are shown in Table 2. COSTDIFF is negatively related to DELIVERY and INNOVATN, but positively related to EFFICIEN. These results provide strong support for the criterionrelated validity of the dimensions of competitive priorities derived earlier through factor analysis. The relationship between COSTDIFF and QUALITY was not found to be statistically significant. This finding is consistent with the findings of a study conducted by Deane, Gargeya, and McDougall, (1990) who found a relationship between manufacturing strategy and business unit strategy for the price leaders but not for the quality leaders. The lack of a statistically significant relationship between COSTDIFF and QUALITY in our study is probably a result of ranking QUALITY as the most important competitive priority (ranked mostly as \#1 or \#2) by the majority of the plants. In other words, QUALITY was considered equally important by most of the plants and, thereby, QUALITY could not foster differentiation by itself. That is, QUALITY is an "order qualifier" rather than an "order winner" (Hill, 2000). Das and Handfield (1997: 257) also asserted, "Quality for established firms in the global arena is more of an order qualifier than an order winner."

Table 2

Results of Regression Analysis (Dependent Variable $=$ COSTDIFF)

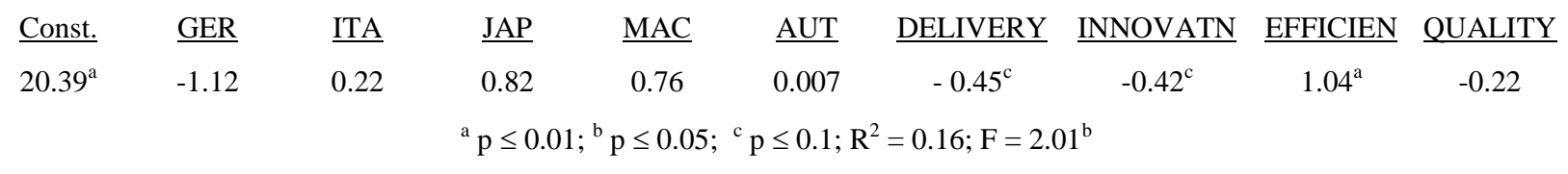

\section{The Administrative Activities}

The two administrative activities, communication of manufacturing strategy to employees at all levels of the organization (COMM) and establishment of formal strategic planning process (FORMAL), were measured using Likert scales (see Appendix B). Each item of a construct was answered by the plant superintendent and a worker using the following five-point scale: Strongly Agree (5), Agree (4), Neutral (3), Disagree (2), and Strongly Disagree (1). For each item, the two responses were averaged to form a plant level response. Each scale was then evaluated for its reliability and unidimensionality. A value of Cronbach's alpha of 0.7 or more was used as a criterion for a reliable scale (Nunnally, 1978). An item was dropped if it did not contribute strongly to the alpha value or if it loaded onto a second factor. Next, we averaged all the items in a scale, which became the value of the variable representing the construct.

As discussed earlier, we believe the two administrative activities (COMM and FORMAL) are important regardless of which dimension of competitive priorities is pursued. If this assertion is true, then we will observe negative correlation between each of these two variables and the four dimensions of competitive priorities. (Note that a lower value of each of the variables DELIVERY, INNOVATN, EFFICIEN, or QUALITY indicates a more important objective).

Table 3 shows partial correlation coefficients. These correlations were controlled for environmental effects (GER, JAP, ITA, MAC, and AUT) as discussed earlier. Table 3 shows each administrative activity variable is negatively related to DELIVERY, INNOVATN, and QUALITY as expected. However, the relationship between each 
administrative activities variable and EFFICIEN was found to be statistically insignificant. That is, plants pursuing the efficiency importance dimension of competitive priorities are not emphasizing communication of the manufacturing strategy to employees or establishment of a formal strategic planning process.

Table 3

Partial Correlation Coefficients" (2-tailed significance in parentheses)

$\begin{array}{lcc}\text { Competitive priority dimensions } & \begin{array}{r}\text { Communication of manufacturing strategy } \\ (\text { COMM) }\end{array} & \begin{array}{r}\text { Formal strategic planning } \\ \text { (FORMAL) }\end{array} \\ \text { Delivery importance (DELIVERY) } & -0.24(0.01) & -0.19(0.06) \\ \text { Innovation importance (INNOVATN) } & -0.21(0.04) & -0.19(0.06) \\ \text { Efficiency importance (EFFICIEN) } & 0.12(0.23) & 0.09(0.34) \\ \text { Quality importance (QUALITY) } & -0.24(0.01) & -0.25(0.01)\end{array}$

* controlled for the variables: GER, JAP, ITA, MAC, and AUT

St. John and Young (1992: 134) observe that "In many manufacturing organizations, managers view their primary task as cost reduction and productivity improvement [efficiency], and they make decisions and take actions that are consistent with the task [even when their strategy focuses on service or innovation]." Viewing cost reduction and productivity improvement (i.e., efficiency importance) as the primary tasks of managers is quite common. Maybe because of this supposedly common "view" of pursuing efficiency importance, managers ignore the need for communicating the manufacturing strategy to employees at all levels of the organization (COMM) or establishing a formal strategic planning process (FORMAL). Another plausible reason for the lack of a significant relationship between the administrative activities and efficiency importance is that the plants emphasizing efficiency importance are generally mechanistic (rather than organic) in nature (Burns \& Stalker, 1961). Therefore, they pay little attention to collaborative decision making through communication and coordination.

\section{Conclusions and Suggestions for Future Research}

We empirically identified and validated the dimensions of competitive priorities. We also found that the efforts put in two administrative activities were dependent on the dimension of competitive priorities pursued by a manufacturing plant. These administrative activities are important regardless of which strategy is pursued because they provide coordinating mechanisms and thus institute strategic consistency within an organization. Skinner (1978) has warned of the problem of strategic inconsistency for many years. This inconsistency is often the cause of "productivity paradox" (Skinner, 1986). In spite of these arguments in favor of instituting strategic consistency at all levels of an organization, empirical evidence points to the fact that it is still lacking in many organizations (Porth, Kathuria, \& Joshi, 1998). The results of our study suggest that strategic inconsistency is most likely to be observed in organizations that compete on the basis of efficiency importance.

The findings of the present study have several important implications for managers. This study provides empirical evidence that delivery, innovation, efficiency and quality are the four dominant sets (dimensions) of competitive priorities that are pursued by manufacturing plants. As mentioned earlier, quality was ranked as the most important competitive priority (ranked mostly as \#1 or \#2) by the majority of the plants. Subsequent analyses showed that quality by itself could not foster differentiation. Managers, therefore, should ensure that their organizations pursue quality management practices. Additionally, they need to pursue other competitive priorities to differentiate them from the competition. Managers should also recognize the importance of the administrative activities in order to minimize strategic inconsistency across different levels within an organization. Particularly, managers of plants that are competing on the basis of efficiency importance need to pay close attention to the two administrative activities.

Our analyses were based on data collected from manufacturing plants; therefore, we cannot make any direct inferences regarding these administrative activities in service organizations. However, we believe that these two administrative activities are crucial in service organizations, be they for-profit or not- for-profit entities, since customer contact is an integral part of the service delivery process. Managers of service organizations, therefore, need to make extra efforts so that competitive priorities are communicated to the people who come in direct contact with the customers during different instances of a service encounter - the moments of truth. 
The present exploratory study provides some insights into how manufacturing organizations are trying to be competitive. However, much empirical research is needed to further our understanding of this important topic. For example, we did not relate competitive priority dimensions to performance achieved. That is, it remains undetermined whether or not an organization's emphasis on a particular competitive priority dimension fosters sustained high performance relative to its competitors. Future studies can answer this question using longitudinal data. The choice of competitive priority is essentially a synthesis of recognizing associated "trade-offs" and exploiting an organization's "core capability." How can an organization go about doing this most effectively? A qualitative process oriented investigation is needed to shed light on this issue. Competitive priorities for an organization are not static; they are dynamic and change over time due to shifts in the competitive environment (e.g., e-commerce). Organizations are incessantly trying to gain competitive advantage by differentiating themselves by offering unique product-service bundles that are hard to imitate. The dimensions of competitive priorities that we observe today will change as time progresses. We hope that future research will track this progression and investigate the forces driving this evolution.

\section{The first author appreciates the faculty research grant provided by the St. Cloud State University.}

\section{References}

1. Adam, E. E. Jr. and P. M. Swamidass, "Assessing operations management from a strategic perspective," Journal of Management, Vol. 15, No. 2, pp. 181-203, 1989.

2. Berry, W. L., Bozarth, C., Hill, T. J. and J. E. Klompmaker, "Factory focus: Segmenting markets from an operations perspective," Journal of Operations Management, Vol. 10, No. 3, pp. 363-387, 1991.

3. Burns, T. and G. M. Stalker, The management of innovation, London: Tavistock, 1961.

4. Cleveland, G., Schroeder, R. G. and J. C. Anderson, "A theory of production competence," Decision Sciences, Vol. 20, No. 4, pp. 655-668, 1989.

5. Corbett, C. and L. V. Wassenhove, "Trade-offs? What trade-offs? Competence and competitiveness in manufacturing strategy," California Management Review, Summer, pp. 107-122, 1993.

6. Das, A. and R. B. Handfield, "Just-in-time and logistics in global sourcing: an empirical study," International Journal of Physical Distribution \& Logistics Management, Vol. 27, No. 3/4, pp. 244-259, 1997.

7. Dean, J. W. Jr. and S. A. Snell, "The strategic use of integrated manufacturing: An empirical examination," Strategic Management Journal, Vol. 17, pp. 459-480, 1996.

8. Deane, R. H., Gargeya, V. B. and P. P. McDougall, "Manufacturing strategy and performance of the new venture firm," In J. E. Ettlie, M. C. Burstein, \& A. Fiegenbaum (Eds.), Manufacturing strategy, the research agenda for the next decade, proceedings of the joint industry university conference on manufacturing strategy, Ann Arbor, MI, pp. 5364, 1990.

9. Dess, G. G., Ireland, R. D. and M. A. Hitt, "Industry effects and strategic management research," Journal of Management, Vol. 16, No. 1, pp. 7-27, 1990.

10. Ferdows, K. and A. De Meyer, "Lasting improvements in manufacturing performance: in search of new theory," Journal of Operations Management, Vol. 9, No. 2, pp. 168-184, 1990.

11. Fitzsimmons, J. A., Kouvelis, K. and D. N. Mallick, "Design strategy and its interface with manufacturing and marketing: A conceptual framework," Journal of Operations Management, Vol. 10, No. 3, pp. 398-415, 1991.

12. Floyd, S. W. and P. J. Lane, "Strategizing throughout the organization: Managing role conflict in strategic renewal," Academy of Management Review, Vol. 25, No. 1, pp. 154-177, 2000.

13. Garvin, D. A. "Manufacturing Strategic Planning," California Management Review, Vol. 35, No. 4, pp. 85-106, 1993.

14. Glynn, M. A. "Innovative genius: a framework for relating individual and organizational intelligences to innovation," Academy of Management Review, Vol. 21, No. 4, pp. 1081-1111, 1996.

15. Govindarajan, V. "A contingency approach to strategy implementation at the business-unit level: integrating administrative mechanisms with strategy," Academy of Management Journal, Vol. 31, No. 4, pp. 828-853, 1988.

16. Hayes, R. H. and S. C. Wheelwright, Restoring our Competitive Edge: Competing through Manufacturing, Wiley, New York, 1984.

17. Hill, T. J. Manufacturing Strategy - Text and Cases, Burr Ridge; IL: Irwin/McGraw-Hill, 2000.

18. Jennings, D. F. and J. R. Lumpkin, “Insights between environmental scanning activities and Porter's generic strategies: an empirical analysis," Journal of Management, Vol. 18, No. 4, pp. 791-803, 1992.

19. Kotha, S. and B. L. Vadlamani, "Assessing generic strategies: an empirical investigation of two competing typologies in discrete manufacturing industries," Strategic Management Journal, Vol. 16, No. 1, pp. 75-83, 1995.

20. Krajewski, L. J. and L. P. Ritzman, Operations Management: Strategy and Analysis, 4th ed. Addison Wesley, Reading, Massachusetts, 1996. 
21. Kumar, K., Subramanian, R. and C. Yauger, "Pure versus hybrid: performance implications of Porter's generic strategies," Health Care Management Review, Vol. 22, No. 4, pp. 47-60, 1997.

22. Leong, G. K., Snyder, D. L. and P. T. Ward, "Research in the process and content of manufacturing strategy," Omega, Vol. 18, No. 2, pp. 109-122, 1990.

23. Nunnally, J. C. Psychometric theory, New York: MacGraw-Hill, 1978.

24. Porter, M. E. Competitive Advantage, New York: The Free Press, 1985.

25. Porter, M. E. The Competitive Advantage of Nations, New York: The Free Press, 1990.

26. Porth, S. J., Kathuria, R. and M. P. Joshi, "Performance impact of the fit between manufacturing priorities of general managers and manufacturing managers," Journal of Business and Economic Studies, Vol. 4, No. 1, pp. 13-35, 1998.

27. Schmenner, R. W. Production /Operations Management, Concepts and Situations, 1st ed. Science Research Associates, Chicago, 1981.

28. Schwab, D. P. “Construct validity in organizational behavior," Research in Organizational Behavior, Vol. 2, No. 1, pp. 3-43, 1980.

29. Skinner, W. "Production under pressure," Harvard Business Review, November-December, pp. 139-146, 1966.

30. Skinner, W. "Manufacturing - Missing link in corporate strategy," Harvard Business Review, May-June, pp. 136-145, 1969.

31. Skinner, W. Manufacturing in the Corporate Strategy, John Wiley \& Sons, New York, 1978.

32. Skinner, W. "The Productivity Paradox," Harvard Business Review, July-August, pp. 55-59, 1986.

33. St. John, C. H. and S. T. Young, "An exploratory study of patterns of priorities and trade-offs among operations managers," Production and Operations Management, Vol. 1, No. 2, pp. 133-150, 1992.

34. Vickery, S. K., Droge, C. and R. R. Markland, "Production competence and business strategy: Do they affect business performance?” Decision Sciences, Vol. 24, No. 2, pp. 435-456, 1993.

35. Vickery, S. K., Droge, C. and R. E. Markland, "Dimensions of manufacturing strength in the furniture industry," Journal of Operations Management, Vol. 15, pp. 317-330, 1997.

36. Ward, P. T., Duray, R., Leong, G. K. and C. Sum, "Business environment, operations strategy, and performance: An empirical study of Singapore manufacturers," Journal of Operations Management, Vol. 13, pp. 99-115, 1995.

37. Ward, P.T., McCreery, J.K., Ritzman, L. P. and D. Sharma, "Competitive priorities in operations management," Decision Sciences, Vol. 29, No. 4, pp. 1035-1046, 1998.

38. Wheelwright, S. C. "Reflecting corporate strategy in manufacturing decisions," Business Horizons, pp. 57-66, 1978.

39. Wood, C. H., Ritzman, L. P. and D. Sharma, "Intended and achieved competitive priorities: measures, frequencies, and financial impact," In J. E. Ettlie, M. C. Burstein, \& A. Fiegenbaum (Eds.), Manufacturing strategy, the research agenda for the next decade, proceedings of the joint industry university conference on manufacturing strategy, Ann Arbor, Michigan, pp. 225-232, 1990.

\section{Appendix A}

\section{Measures of Competitive Priorities, and Low-cost and Differentiation Strategy Variables}

\section{$\underline{\text { Competitive Priorities }}$}

Please rank the importance of the following objectives or goals for manufacturing at your plant over the next five years. Rank \#1 for the most important objective, \#2 for the next most important and so on. You may rank several objectives the same if they are of equal importance.

$\begin{array}{lll}\text { COST } & \text { Rank } & \text { Low unit cost } \\ \text { NEWPROD } & - & \begin{array}{l}\text { Ability to rapidly introduce new products or make design changes } \\ \text { Vbility to make rapid volume changes } \\ \text { VOLCHNG }\end{array} \\ \text { CONSQUAL } & - & \begin{array}{l}\text { Consistent quality } \\ \text { HIGHPERF }\end{array} \\ \text { FASTDEL } & - & \text { High performance products } \\ \text { DEPENDEL } & - & \text { Fast deliveries } \\ \text { CYCLETM } & - & \text { Dependable delivery } \\ \text { Low manufacturing cycle time }\end{array}$

Low-cost and Differentiation Strategy

Please circle the number that indicates your opinion about how the products produced at this plant compare to their competition. 1 = significantly lower, 2 = lower, $3=$ about the same, 4 = higher, $5=$ significantly higher.

$\begin{array}{lllllll}\text { SELPRICE } & 1 & 2 & 3 & 4 & 5 & \text { Product selling price. } \\ \text { R\&D } & 1 & 2 & 3 & 4 & 5 & \text { Percent of sales spent on R \& D. } \\ \text { MKTEXP } & 1 & 2 & 3 & 4 & 5 & \text { Percent of sales spent on marketing expenses. } \\ \text { PRDQUAL } & 1 & 2 & 3 & 4 & 5 & \text { Product quality. }\end{array}$




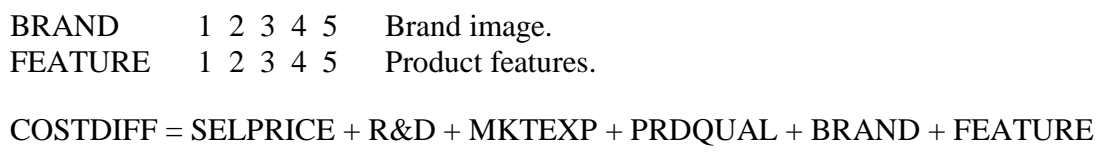

Appendix B

Scales used to Measure Administrative Activities

\begin{tabular}{|c|c|c|}
\hline$\underline{\text { Variable }}$ & $\underline{\text { Scales }}$ & $\underline{\text { Item questions }}$ \\
\hline $\begin{array}{l}\text { COMM } \\
\alpha=0.91\end{array}$ & $\begin{array}{l}\text { Communication of } \\
\text { manufacturing strate- } \\
\text { gy }\end{array}$ & $\begin{array}{l}\text { - In our plant, goals, objectives and strategies are communicated to me. } \\
\text { - Strategies and goals are communicated primarily to managers. }{ }^{\text {a }} \\
\text { - I know how we are planning to be competitive at this plant. } \\
\text { - I understand the long-run competitive strategy of this plant. }\end{array}$ \\
\hline $\begin{array}{l}\text { FORMAL } \\
\alpha=0.90\end{array}$ & $\begin{array}{l}\text { Formal strategic } \\
\text { planning process }\end{array}$ & $\begin{array}{l}\text { - Our plant has a formal strategic planning process which results in a } \\
\text { written mission, long-range goals and strategies for implementation. } \\
\text { - Plant management is not included in the formal strategic planning } \\
\text { process. It is conducted at higher levels in the corporation. } \\
\text { - The plant has a strategic plan which is put in writing. } \\
\text { - Plant management routinely reviews and updates a long-range strategic } \\
\text { plan. } \\
\text { - The plant has an informal strategy which is not very well defined. }\end{array}$ \\
\hline
\end{tabular}

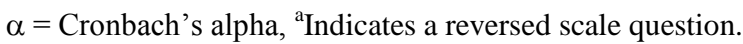

All scale questions use a 5-point likert response scale where $1=\mathrm{I}$ strongly disagree and $5=\mathrm{I}$ strongly agree. 